\title{
QUANTITATIVE EVALUATION OF THE MICROSTRUCTURE AND MECHANICAL PROPERTIES OF HOT ROLLED 23MnB4 STEEL GRADE FOR COLD UPSETTING
}

\begin{abstract}
The article presents the results of tests of influence of the thermo-mechanical treatment parameters on the mechanical properties and microstructure of steel 23MnB4 for cold-upsetting. Measurements of the ferrite grains and pearlite colonies were conducted with the use of Met-Ilo program supplemented by additional procedures dedicated to structure analysis of ferritic-pearlitic steel. The process of rolling was conducted in simulation in semi-continuous finishing train arrangement with different temperature and cooling rate. Elaborated procedure of quantitative analysis of microstructure and conducted mechanical properties tests will be used during preparations of modified technologies of wire rod rolling to prepare products made of steel, the microstructure of which is characterised higher utility properties.
\end{abstract}

Keywords: 23MnB4 steel, hot rolling, microstructure, quantitative metallography, grain size

\section{Introduction}

Low-carbon steel types intended for cold-upsetting are rolled in modern continuous systems [1,2]. Linear velocity of rolling wire rod in such systems equals up to $100 \mathrm{~m} / \mathrm{s}$. In such dynamic conditions the parameters of rolling process and later cooling process play an important role in shaping the microstructure and mechanical properties. Constant growth in requirements concerning properties of the products needs improvement of manufacturing technology. Conduction of experiments in order to choose the optimal parameters of the process on industrial production lines is very difficult due to the need $\mathrm{f}$ application of a big amount of material in a singular process. That is why laboratory rolling mills are constructed to illustrate the conditions of the real rolling process in a more detailed way. An example of the above mentioned test can be semi-industrial simulation of manufacturing processes of alloys and metal products (LPS) in IMŻ Gliwice (Institute for Ferrous Metallurgy) [2] and semi-continuous laboratory mill for rolling bars in VSB - Technical University of Ostrava, Faculty of Metallurgy and Materials Engineering, Czech Republic [3]. Potential applications of semi-continuous laboratory are simulations of industrial rolling conditions, choice of optimal process parameters and regulated cooling of steel and alloys non-ferrous alloys. Cooling rate on industrial production line for rolling wire rod can be regulated on "Stelmor" line where in the final part the loops of the wire rod are arranged. Increase of cooling rate may cause the increase of resistance in steel with satisfactory plasticity because the fine-grained ferritic-pearlitic microstructure without the presence of bainite. The aim of the paper was the analysis of the influence of rolling process parameters-temperature and cooling rate on quantitative description of microstructure and mechanical properties of steel $23 \mathrm{MnB} 4$. Measurements of the ferrite grains and pearlite colonies were conducted with the use of METILO program [4], supplemented by additional procedures dedicated to structure analysis of ferriticpearlitic steel.

\section{Methodology}

Materials for tests were rods made of steel 23MnB4 meant for wire rods for cold-upsetting. Physical simulation of heatplastic treatment was determine on dilatometer [5]. Samples we heated up to $900^{\circ} \mathrm{C}$, deformed with a strain $\varepsilon=0.3$ and cooling with varied rates from 0.1 to $10^{\circ} \mathrm{C} / \mathrm{s}^{-1}$. The conditions of physical simulation in continuous finishing train arrangement of four rolling stands in a laboratory of Faculty of Metallurgy and Materials Engineering VSB [1] Ostrava were close to real conditions present on industrial line of rolling wire rod [2]. Before rolling the rods were heated to a temperature of $1100^{\circ} \mathrm{C}$ and held for 30 minutes. Initial rolling of rods was conducted on 6 breakdown passes from diameter of $ø 30 \mathrm{~mm}$ to $\varnothing 15.8$ on a reversing rougher. Finish rolling was performed on four-rolling stands of continuous finishing mill from diameter of ø15.6 mm to $\varnothing 9.8 \mathrm{~mm}$. Finish rolling was conducted in three different 
temperature options: $750^{\circ} \mathrm{C}, 900^{\circ} \mathrm{C}$ and $1020^{\circ} \mathrm{C}$. There were two different types of cooling after rolling applied:

- cooling in air to a temperature of $550^{\circ} \mathrm{C}$, then with furnace with a rate of $0.4^{\circ} \mathrm{C} / \mathrm{s}$ to $400^{\circ} \mathrm{C}$ and next in air to a room temperature.

- slow cooling with furnace with a rate of $0.4^{\circ} \mathrm{C} / \mathrm{s}$ to $400^{\circ} \mathrm{C}$ and next in air to a room temperature.

Mechanical properties were determine on testing machine Zwick/Roell Z100. Metallographic test was conducted on light microscope type Olympus GX51 with magnification in a range of $500 \div 1000 \times$. Structure of samples for tests was visible with the use of classic set of chemistry processing for this type of steel and registered with the use of light microscope. In order to eliminate the shadow effect present on the registered images there was the so-called function procedure of correction applied which is available in the METILO program. Colonies of pearlite on images corrected in this way have significantly different level of greyness from the background which cannot be analysed. It enables a correct detection of those colonies on the basis of binarisation only. Conducted tests have shown that the best effect is achieved by automatic binarisation with the use of k-means method.

It was more difficult to detect the grain boundaries of ferrite due to their uneven etching. Initial detection was conducted on the image from which the colonies of pearlite were removed. The achieved image underwent automatic local binarisation k-means in 4096 areas. Further actions contained skeletonisa- tion, clipping the ends of the skeleton, marking the logical sum of the skeleton images and the outline of the pearlite colony, marking the spacing function and the application of the method of watershed. Despite the application of such complex procedure it was not always possible to detect all the grain boundaries of ferrite correctly. That is why it is additionally possible in the program Met-Ilo to manually correct the boundaries. A number of stereological parameters were determined, characteristic of dual-phase microstructure materials, of which the following are presented in this publication:

- $\quad$ mean area of grain plane section $\bar{A}\left[\mu \mathrm{m}^{2}\right],\left(\bar{A}_{P}-\bar{A}, \bar{A}_{F}-\right.$ ferrite grains size),

- $\quad$ variability factor of the grain plane section area $v(A)[\%]$, - colonies of pearlite volume $\bar{A}_{A p}[\%]$.

\section{Results}

Microstructure of the example sample after physical simulation were presented on Fig. 2. Results of quantitative analysis of microstructure are shown in Table 1. It was stated that together with the increase of the cooling rate from 0.1 to $5^{\circ} \mathrm{C} / \mathrm{s}^{-1}$, the input of pearlite in microstructure increases whereas the mean size of pearlite colonies $\left(\bar{A}_{P}\right)$ and ferrite grains significantly decreases $\left(\bar{A}_{F}\right)$. Similarly, variability factor of pearlite grain size $v\left(A_{P}\right)$ and ferrite grain size $v\left(A_{F}\right)$ decrease with increasing of cooling rate.

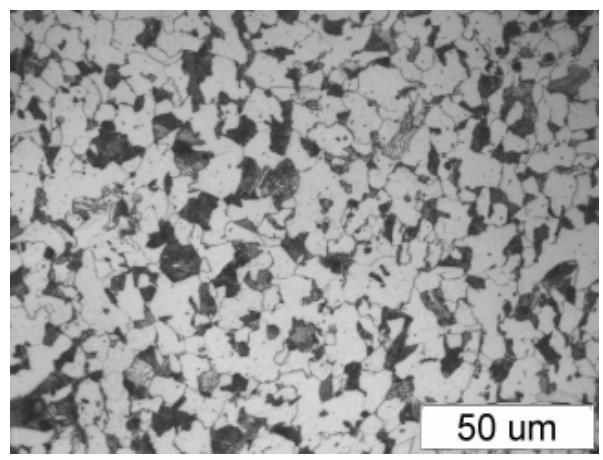

a)

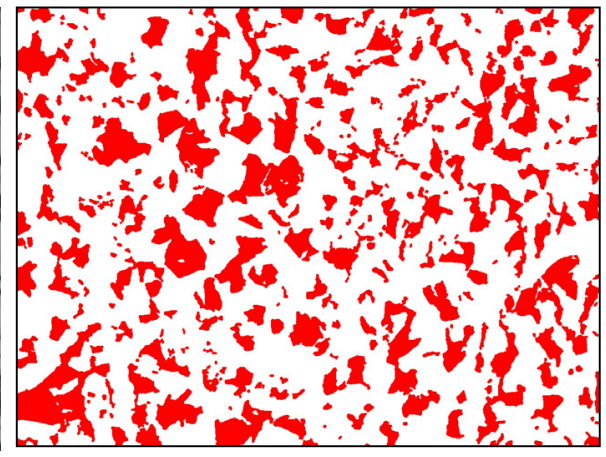

b)

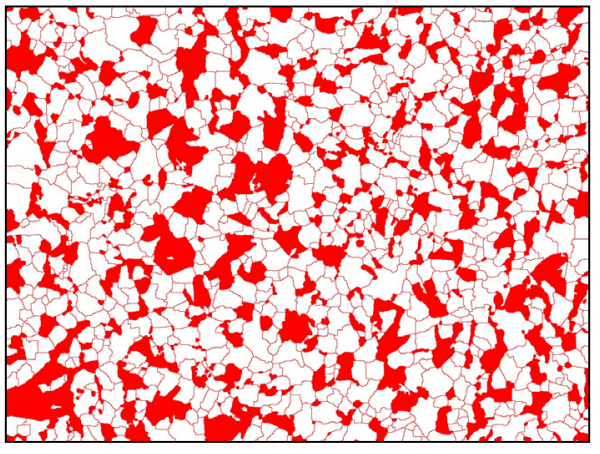

c)

Fig.1. Example of 23MnB4 steel microstructure (a) and detection of a colony of pearlite (a) and grains of ferrite (b) in Metllo programme

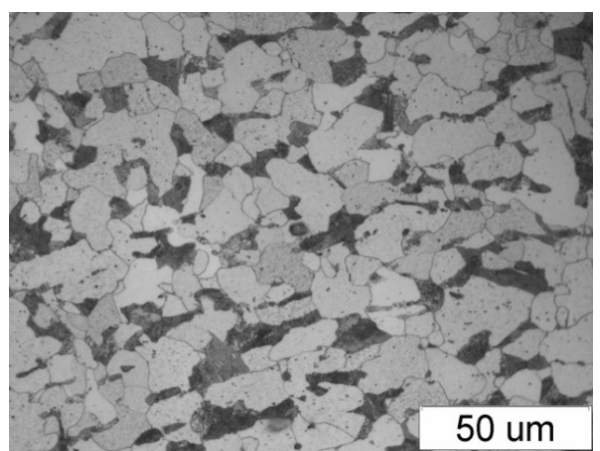

a)

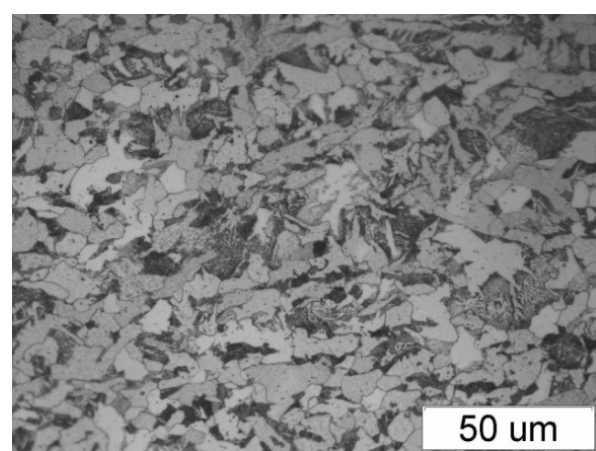

b)

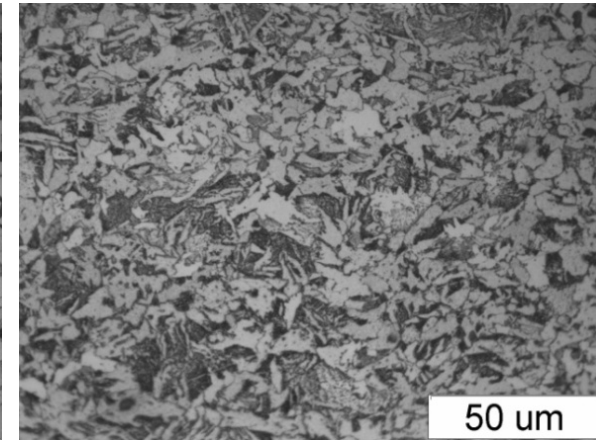

c)

Fig. 2. Microstructure of $23 \mathrm{MnB} 4$ after cooling with a rate: $1^{\circ} \mathrm{C} / \mathrm{s}(\mathrm{a}), \mathrm{b}-5^{\circ} \mathrm{C} / \mathrm{s}(\mathrm{b})$ and $10^{\circ} \mathrm{C} / \mathrm{s}(\mathrm{c})$ 
TABLE 1 @ ferrite during sample cooling with the rate of $5^{\circ} \mathrm{C} / \mathrm{s}$ starts at

Results of quantitative descriptions of microstructure after physical simulation on dilatometer

\begin{tabular}{|c|c|c|c|c|c|}
\hline $\begin{array}{c}\text { Cooling } \\
\text { rate } \\
{\left[{ }^{\circ} \mathrm{C} / \mathrm{s}\right]}\end{array}$ & $\begin{array}{l}\text { Pearlite } \\
\text { volume } \\
\bar{A}_{A p}[\%]\end{array}$ & $\begin{array}{c}\text { Pearlite } \\
\text { grain size } \\
\bar{A}_{P}\left[\mu \mathrm{m}^{2}\right]\end{array}$ & $\begin{array}{c}\text { Variability } \\
\text { factor of } \\
\text { pearlite grain } \\
\text { size } v\left(A_{P}\right)[\%]\end{array}$ & $\begin{array}{c}\text { Ferrite } \\
\text { grain size } \\
\bar{A}_{F}\left[\mu \mathrm{m}^{2}\right]\end{array}$ & \begin{tabular}{|c|} 
Variability \\
factor of fer- \\
rite grain size \\
$v\left(A_{F}\right)[\%]$
\end{tabular} \\
\hline 0.1 & 21,2 & 20.4 & 132 & 22.2 & 79.0 \\
\hline 1 & 22.7 & 15.3 & 165 & 19.3 & 86.3 \\
\hline 5 & 24.7 & 7.3 & 220 & 11.4 & 95.6 \\
\hline
\end{tabular}

Temperature changes in time function were registered after rolling and cooling in air. Rods cooled in air reached a cooling rate of mean $5^{\circ} \mathrm{C} / \mathrm{s}$ (in a range from 800 to $600^{\circ} \mathrm{C}$ ) and with such cooling rate it is possible to achieve ferritic-pearlitic structure which can be proved by observed changes on registered cooling curve (Fig. 3) and microstructure tests (Fig. 4). Cooling with a rate of above $5^{\circ} \mathrm{C} / \mathrm{s}$ causes separation of bainite in the microstructure of steel $23 \mathrm{MnB} 4$. Transformation of austenite a temperature of $675^{\circ} \mathrm{C}$, whereas the pearlite transformation starts at a temperature of $640^{\circ} \mathrm{C}$.

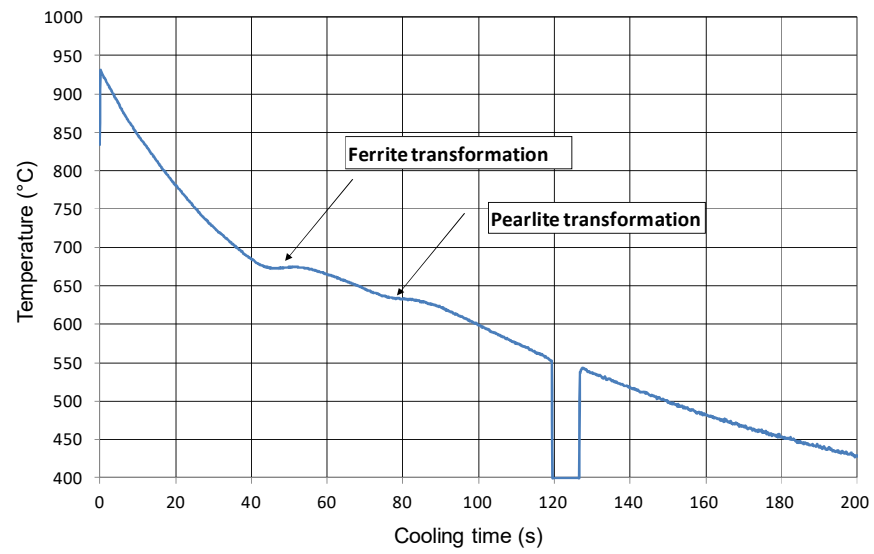

Fig. 3. Cooling curve registered with the use of thermal scanners after rolling at temperature $1020^{\circ} \mathrm{C}$

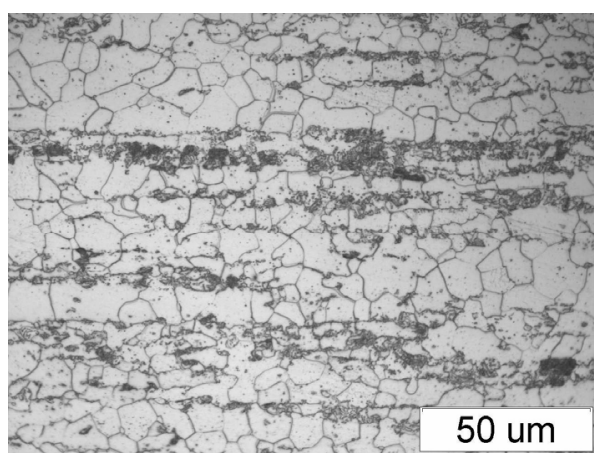

a) $750^{\circ} \mathrm{C}$

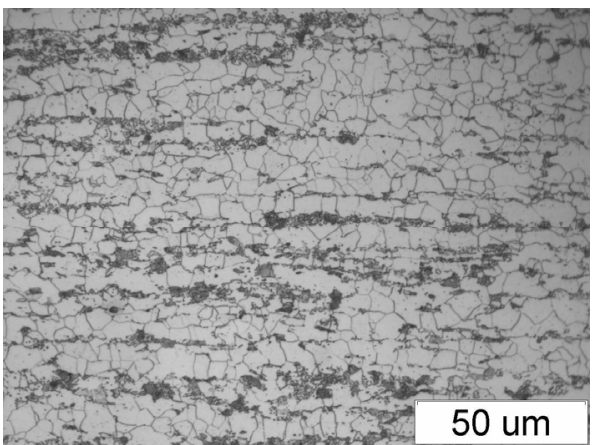

c) $750^{\circ} \mathrm{C}$

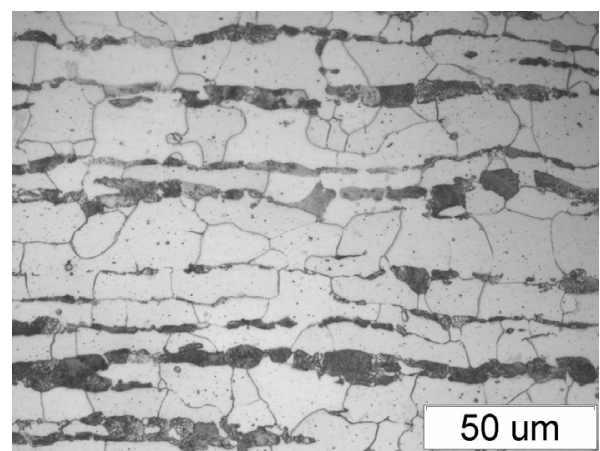

b) $900^{\circ} \mathrm{C}$

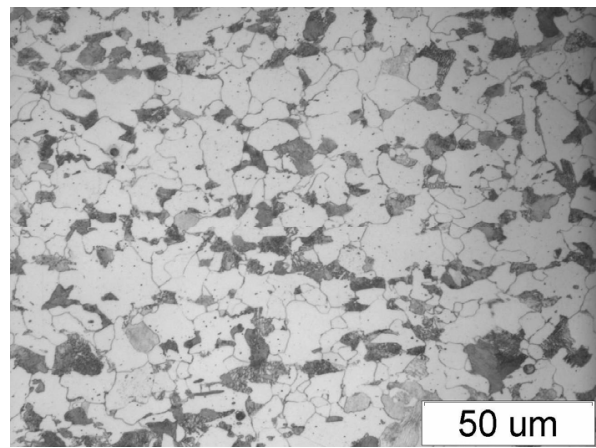

d) $900^{\circ} \mathrm{C}$

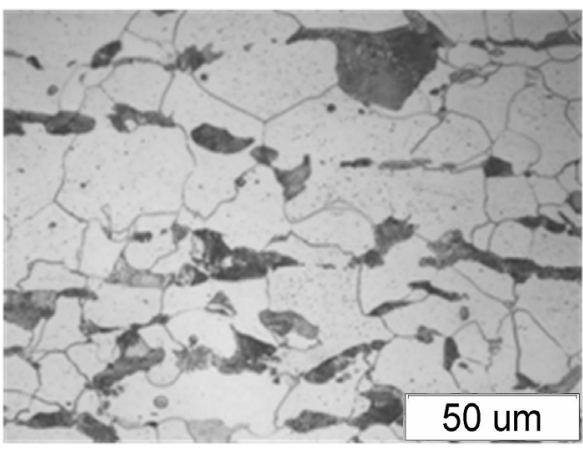

c) $1020^{\circ} \mathrm{C}$

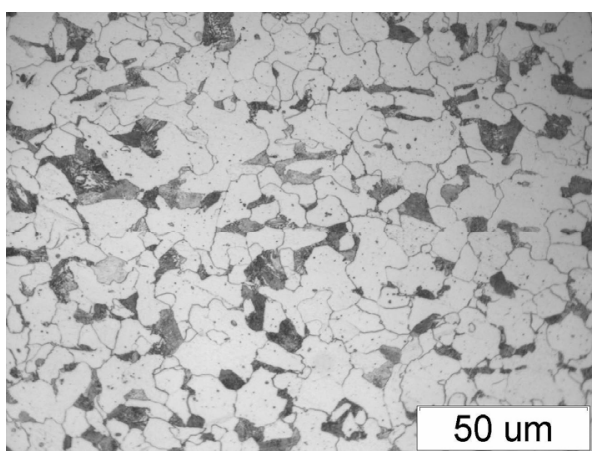

e) $1020^{\circ} \mathrm{C}$

Fig. 4. Microstructure of rod from 23MnB4 steel after rolling and cooling in air ( $a, b$ and $c)$ and cooled in furnace (a, b and c) (longitudinal section)

The microstructure of steel $23 \mathrm{MnB} 4$ for wire rods significantly depends on the parameters of rolling and cooling (Table 2). A series of stereological parameters was marked in the form of mean values (Table 2) and statistical distributions (Fig. 4). Samples cooled slowly in furnace after rolling are characterised with higher mean size of ferrite grains and colonies of pearlite. It was found that the slight increase of the amount of pearlite occurs with the elevation of temperature of the end of rolling and the increase of cooling rate. Together with the elevation of rolling temperature from $750^{\circ} \mathrm{C}$ to $1020^{\circ} \mathrm{C}$ the mean grain size of ferrite increases from $7.1 \mathrm{~mm}^{2}$ to $26.5 \mathrm{~mm}^{2}$ and the mean colony of pearlite size from $5.4 \mathrm{~mm}^{2}$ to $30.9 \mathrm{~mm}^{2}$ after in air cooling. After cooling with furnace the size of ferrite and pearlite grains get, on mean, 50\% higher. The statistical distributions were elaborated which present the frequency of occurrence of pearlite colonies and ferrite grains in different size classes in diameter for various options of heat-plastic treatment (Fig. 5). Heterogeneity of the size of the pearlite colony is 2 times bigger in comparison with 
Results of quantitative analysis of ferritic-pearlitic microstructure

\begin{tabular}{|c|c|c|c|c|c|}
\hline $\begin{array}{c}\text { Rolling temperature }\left[{ }^{\circ} \mathrm{C}\right] \\
/ \text { cooling rate }\left[{ }^{\circ} \mathrm{C} / \mathrm{s}\right]\end{array}$ & $\begin{array}{c}\text { Pearlite volume } \\
\bar{A}_{A p}[\%]\end{array}$ & $\begin{array}{c}\text { Pearlite grain size } \\
\bar{A}_{P}\left[\mu \mathrm{m}^{2}\right]\end{array}$ & $\begin{array}{c}\text { Variability factor of pearlite } \\
\text { grain size } v\left(A_{P}\right)[\%]\end{array}$ & $\begin{array}{c}\text { Ferrite grain size } \\
\bar{A}_{F}\left[\mu \mathrm{m}^{2}\right]\end{array}$ & $\begin{array}{c}\text { Variability factor of ferrite } \\
\text { grain size } v\left(A_{F}\right)[\%]\end{array}$ \\
\hline $750^{\circ} \mathrm{C}-5^{\circ} \mathrm{C} / \mathrm{s}$ & 20.4 & 5.4 & 187 & 7.1 & 97.4 \\
\hline $900^{\circ} \mathrm{C}-5^{\circ} \mathrm{C} / \mathrm{s}$ & 22.2 & 16.3 & 197 & 22.7 & 98,2 \\
\hline $1020^{\circ} \mathrm{C}-5^{\circ} \mathrm{C} / \mathrm{s}$ & 25.7 & 20.9 & 214 & 26.5 & 102.3 \\
\hline $750^{\circ} \mathrm{C}-0.4^{\circ} \mathrm{C} / \mathrm{s}$ & 18.2 & 7.3 & 161 & 11.1 & 83.0 \\
\hline $900^{\circ} \mathrm{C}-0.4^{\circ} \mathrm{C} / \mathrm{s}$ & 21.1 & 20.3 & 182 & 28.2 & 84.3 \\
\hline $1020^{\circ} \mathrm{C}-0.4^{\circ} \mathrm{C} / \mathrm{s}$ & 23.2 & 30.9 & 191 & 40.9 & 90.5 \\
\hline
\end{tabular}

heterogeneity of the ferrite grain size, which is proved by the values of variability factor of pearlite grain size $v\left(A_{P}\right)$ and ferrite grain $v\left(A_{F}\right)$. Both factor increases with rise of rolling temperature and cooling rate, as in dilatometric tests.

Achieved results of the quantitative microstructure assessment were correlated with the parameters of the process and mechanical properties and then mathematical dependencies were marked. Results of mechanical properties of samples after rolling are presented in Table 3. In samples cooled in air the course of changes in properties in monotonic. The biggest yield stress $\left(\mathrm{YS}_{0.2}\right)$ can be found in samples rolled in temperature of $750^{\circ} \mathrm{C}$ and decrease with the increase of rolling temperature. Ultimate tensile strength (UTS) achieved after rolling in $750^{\circ} \mathrm{C}$ and $900^{\circ} \mathrm{C}$ is comparably similar. Samples cooled slowly with furnace show lower values ultimate tensile strength (UTS) and yield stress $\left(\mathrm{YS}_{0.2}\right)$ in comparison with the previously described samples. Elongation of samples (A) reduction in area were comparable for using rolling temperature range and cooling rate. In this option the biggest strength properties can be found in samples rolled in temperature of $750^{\circ} \mathrm{C}$. Those values significantly decrease with the increase of temperature. Dependency of the yield stress $\mathrm{YS}_{0.2}$ from the pearlite grain size $\left(\bar{A}_{P}\right)$ and ferrite grain size $\left(\bar{A}_{F}\right)$ can be described with a good approximation with the use of power function (Fig. 6).

TABLE 3

Tensile test results of the rolled samples

\begin{tabular}{|c|c|c|c|c|}
\hline $\begin{array}{c}\text { Rolling temperature-/ } \\
\text { cooling rate }\end{array}$ & $\begin{array}{c}\mathbf{Y S}_{\mathbf{0 . 2}} \\
{[\mathbf{M P a}]}\end{array}$ & $\begin{array}{c}\text { UTS } \\
{[\mathbf{M P a}]}\end{array}$ & $\begin{array}{c}\mathbf{A}_{\mathbf{5}} \\
{[\mathbf{\%}]}\end{array}$ & $\begin{array}{c}\mathbf{Z} \\
{[\%]}\end{array}$ \\
\hline $750^{\circ} \mathrm{C} /\left(5^{\circ} / \mathrm{s}\right)$ & 445.2 & 529.8 & 28.0 & 65.0 \\
\hline $900^{\circ} \mathrm{C} /\left(5^{\circ} / \mathrm{s}\right)$ & 366.3 & 531.2 & 27.1 & 60.8 \\
\hline $1020^{\circ} \mathrm{C} /\left(5^{\circ} / \mathrm{s}\right)$ & 356.2 & 512.3 & 27.8 & 64.2 \\
\hline $750^{\circ} \mathrm{C} /\left(0.4^{\circ} / \mathrm{s}\right)$ & 380.0 & 494.3 & 29.5 & 68.0 \\
\hline $900^{\circ} \mathrm{C} /\left(0.4^{\circ} / \mathrm{s}\right)$ & 322.0 & 477.5 & 29.2 & 67.0 \\
\hline $1020^{\circ} \mathrm{C} /(0.4 \%)$ & 297.0 & 478.6 & 27.6 & 69.8 \\
\hline
\end{tabular}

Samples for cold-upsetting with sizes $\varnothing 8 \times 12 \mathrm{~mm}$ were taken from rods. Tests were performed on hydraulic press ZDJT 30 with maximum pressure of 30 tonnes. Upsetting was conducted to $1 / 3$ of the height (deformation of $33 \%$ ) and to $2 / 3$ of height (deformation of 66\%) (Fig. 7) For all using parameters of rolling there were no cracks found which can positively classify the rolled rods from steel $23 \mathrm{MnB} 4$ in accordance with the applied criterion of acceptance.

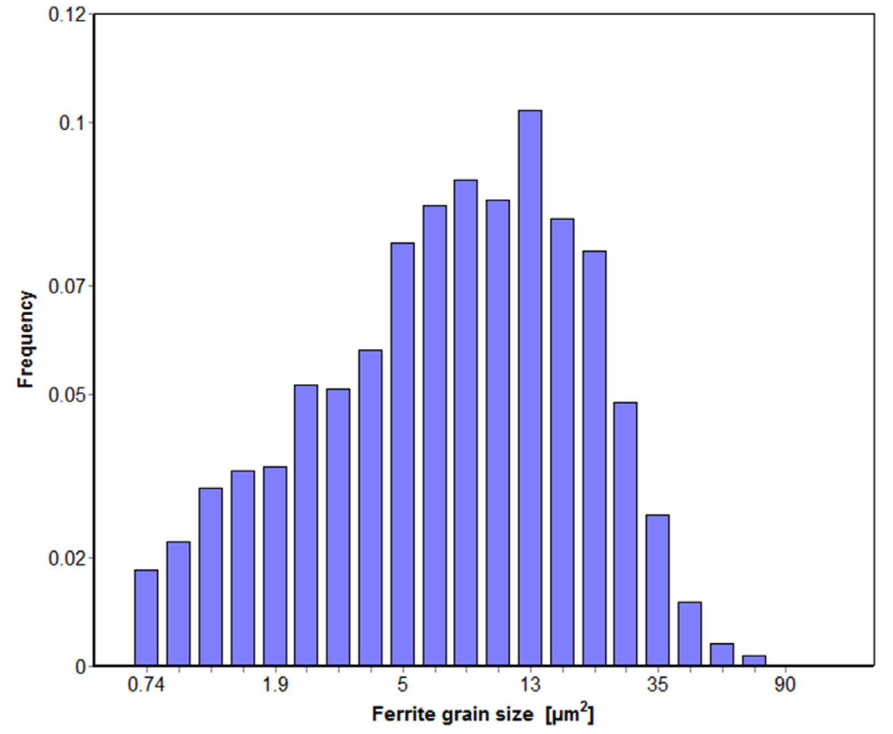

a)

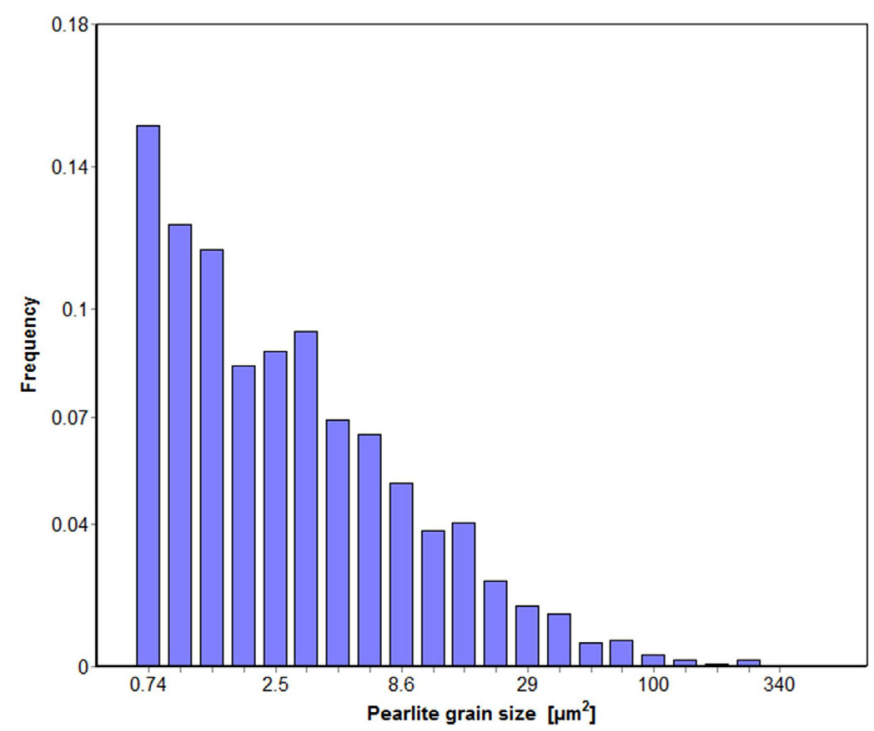

b)

Fig. 5. Statistical distribution of the pearlite grain size $\left(A_{P}\right)$ (a) and ferrite grain size $\left(A_{F}\right)$ (b) in microstructure of investiagated steel after rolling at temperature $760^{\circ} \mathrm{C}$ 


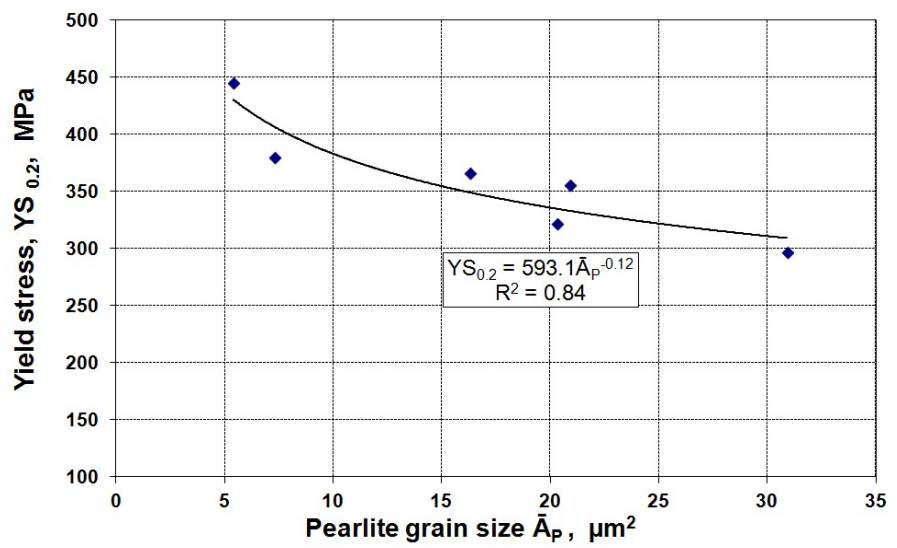

a)

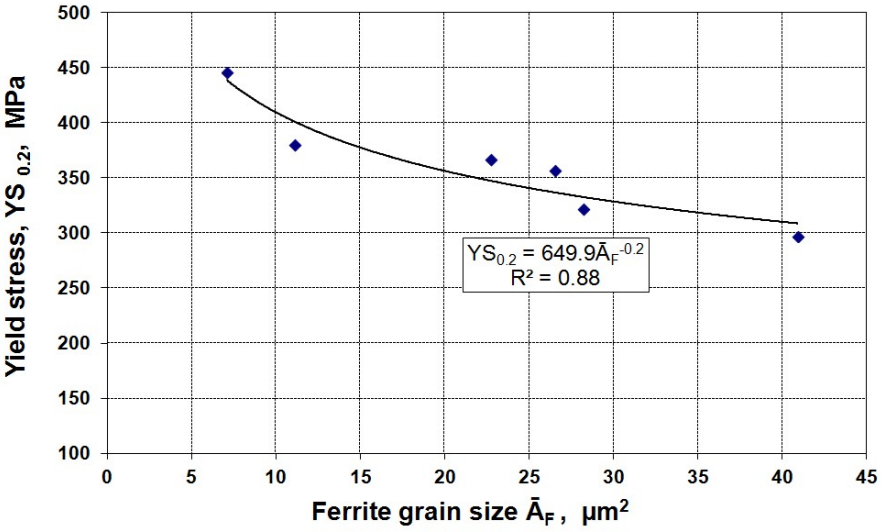

b)

Fig. 6. Dependency of the yield stress $\mathrm{YS}_{0.2}$ from the mean pearlite grain size $\left(\bar{A}_{P}\right)$ (a) and mean ferrite grain size $\left(\bar{A}_{F}\right)(\mathrm{b})$

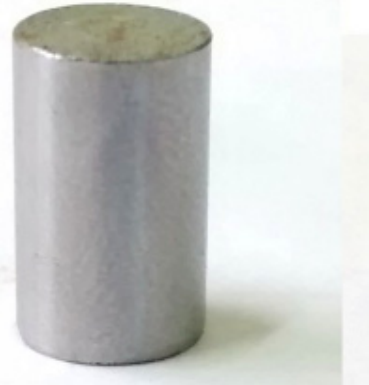

a)

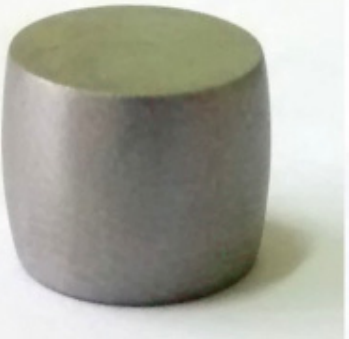

b)

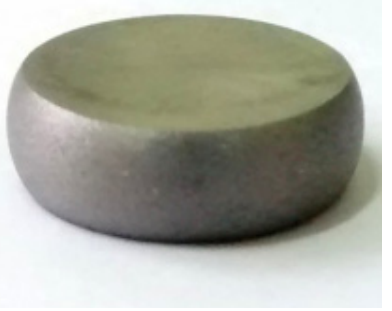

c)

Fig. 7. View of sample from rolled rod at temperature of $750^{\circ} \mathrm{C}$; a) before upsetting b) after upsetting up to $2 / 3$ of initial height c) after upsetting up to $1 / 3$ of initial height

\section{Conclusion}

It was proved that the preparation of a quantity measurement procedure in MetIlo program makes it possible for precise marking of distributions and mean sizes of ferrite and colonies of pearlite in microstructure of steel $23 \mathrm{MnB} 4$. Results of tests show that the growth of cooling rate of samples from steel 23MnB4 leads to grain refinement but at the same time an increase of heterogeneity of grain size occurs (Table 1). After cooling at a rate of $5^{\circ} \mathrm{C} / \mathrm{s}$ the microstructure consists of fine grains of ferrite and pearlite. Further increase of cooling rate leads to formation of bainite islands which as a consequence may lead to decrease of plasticity of tested steel $23 \mathrm{MnB} 4$. The conducted tests have shown a significant influence of rolling temperature and cooling rate on the microstructure and mechanical properties of steel 23MnB4 meant for cold-upsetting (Tables 2, and 3). At present, the temperature of the end of rolling equals $900^{\circ} \mathrm{C}$, and cooling rate on Stelmor line is very small and equals about $0.4^{\circ} \mathrm{C} / \mathrm{s}$. In the presented paper it was stated that if a lower temperature of rolling and a bigger rate of cooling is applied products with better yield stress and ultimate tensile strength without the loss in plasticity can be achieved (Table 3). Significantly meaningful increase can be achieved after lowering the rolling temperature to $750^{\circ} \mathrm{C}$. Increase of cooling rate from 0.4 to an average $5{ }^{\circ} \mathrm{C} / \mathrm{s}$ enables a $50 \%$ decrease in grain sizes with the simultaneous increase of heterogeneity. Correctly conducted process of production wire rod meant for cold-upsetting from steel 23MnB4 should allow for the achievement of material which, after being put into upsetting test, should provide properties of the ready product in the range of relative plastic strain of about $33 \%$ (2/3 of the initial height). However, due to the constantly growing requirements of the recipients the properties of the manufactured wire rod need to be constantly improved even to upsetting to $1 / 3$ of the initial height of $66 \%$. It can be stated that the decrease of rolling temperature and increase of cooling rate which leads to grain refinement in microstructure of tested steel allows for achievement of products with improved strength properties with the required plasticity. Achieved results of tests will be used to determine the mathematical dependencies between parameters of rolling process, mechanical properties and quantitative description of the ferritic-pearlitic microstructure such as presented in article [6,7]. It will make the process of designing the modified technology of producing wire rod with elevated mechanical properties.

\section{Acknowledgements}

This work was supported by Research Project of The National Centre for Research and Development of Poland No PBS/A5/32/2013. 
556

\section{REFERENCES}

[1] F. Grosman, D. Woźniak, Hutnik-Wiadomości Hutniczne 3, 97 104 (2001)

[2] K. Laber, H. Dyja, B. Koczurkiewicz, Materials Testing 57 (4), 301-305 (2015)

[3] P. Kawulok, R. Kawulok, I. Schindler, S. Rusz, J. Kliber, P. Unucka, K.M. Čmiel, Metalurgija-Metallurgy 3, 299-302 (2014).
[4] J. Szala, Application of computer image analysis method in the quantitative analysis of materials microstructure, (2000), Silesian University of Technology, Gliwice.

[5] B. Koczurkiewicz, A. Stefanik, METAL 2015: 24th International Conference on Metallurgy and Materials 868-873 (2015) Brno, Czech Republic

[6] D. Kuc, G. Niewielski, J. Cwajna, Materials Characterization 56, 318-324 (2006).

[7] D. Kuc, J. Gawąd, Arch. Metall. Mater. 56 (2), 523-532 (2011). 